\title{
Influence of Digital Competence on Perceived Stress, Burnout and Well-Being Among Students Studying Online During the COVID-I9 Lockdown: A 4-Country Perspective
}

\author{
Vilmantè Kumpikaitè- \\ Valiūnienè (D) \\ Imran Aslan ${ }^{2}$ \\ Jurga Duobiené \\ Ewa Glińska ${ }^{3}$ \\ Victor Anandkumar (iD ${ }^{4}$ \\ 'School of Economics and Business, \\ Kaunas University of Technology, Kaunas, \\ Lithuania; ${ }^{2}$ Faculty of Health Sciences, \\ Bingöl University, Bingöl, Turkey; ${ }^{3}$ Faculty \\ of Engineering Management, Bialystok \\ University of Technology, Bialystok, \\ Poland; ${ }^{4}$ School of Management, \\ Pondicherry University, Pondicherry, \\ India
}

\begin{abstract}
Purpose: This paper aims to reveal the influence of digital competence on perceived stress, burnout and well-being among students studying online during the COVID-19 lockdown in the spring of 2020 and to compare this influence on the basis of studies conducted in four countries.

Methods: An exploratory study was conducted in Poland, Lithuania, Turkey and India using a cross-sectional research design. A total of 1097 respondents took part in the survey. Wellbeing was measured by the World Health Organization (WHO) Well-being Index, stress was evaluated using a psychological stress measure (PSM-9) instrument, burnout was evaluated using the Copenhagen Burnout inventory, and digital competence was measured by the Digital Competency Profiler (DCP).

Results: The results revealed that social and informational dimensions of digital competencies had a positive influence on dealing with stress or burnout and improved well-being of students studying online during the COVID-19 lockdown. Moreover, the analysis on a country level highlighted that with regard to dealing with stress and burnout, the epistemological dimension of digital competence was the most important for Lithuanians and Indians, the informational dimension for Polish students and the social dimension for Turkish students.

Conclusion: The findings support the importance of digital competence on perceived stress, burnout and well-being among students studying online during the COVID-19 lockdown and propose deeper research directions on this phenomenon.
\end{abstract}

Keywords: digital competence, online learning, stress, burnout, well-being, COVID-19

\section{Introduction}

In February and March 2020, the introduction of social distancing, closing down of majority of shops, restaurants, gyms, sport facilities, theatres, and limited travel and socializing became key measures taken to prevent the spread of COVID-19. The global COVID-19 pandemic affected 1.6 billion students, who at the peak of the crisis, could not study in a traditional way in $2020 .^{1-3}$ Schools and universities moved from physical to online learning. This is described as online education that takes place when a teacher and students are separated by a physical distance, and the Internet is used to connect them. ${ }^{4}$ In the majority of cases, this transfer was done without a proper preparation and/or even providing just a limited support for

\footnotetext{
Correspondence: Vilmantė KumpikaitėValiūnienè

School of Economics and Business,

Kaunas University of Technology,

Gedimino g. 50-2II, Kaunas, LT-44249,

Lithuania

Tel +37061121952

Email vilmante.kumpikaite@ktu.It
} 
educators and students. ${ }^{5}$ The use of digital Learning Management Systems (LMS) has recently turned into a necessity, transforming educational institutions and the habits of educators and students. Students have suddenly had to force themselves to take responsibility for their own learning although they get together with the educators through online platforms. ${ }^{6}$ The fear of pandemic and related changes influenced the well-being of students. In a monetary value of the total well-being cost (that is, health-related costs due to economic and social impact on people), the cost of losing well-being and experiencing high stress levels is indicated to be around $£ 43$ per adult per day in the UK. ${ }^{7}$ Thus, better well-being would decrease government and healthcare expenditure as well as the mortality rate.

The already numerous studies on COVID-19's role on students' well-being and its related issues have been conducted in different countries. Several main streams of studies could be highlighted. Firstly, issues of well-being and factors such as stress, anxiety and depression were explored. These studies revealed COVID-19-induced increased stress, anxiety and depression as well as lower well-being amid pandemic among students in Bangladesh, ${ }^{8}$ China, ${ }^{9,10}$ Saudi Arabia, ${ }^{11}$ the USA, ${ }^{12}$ Turkey, ${ }^{13}$ and Vietnam. ${ }^{14}$

Secondly, studies related to reasons behind stress could be depicted. Among the main factors, isolation, economic and social changes, career concerns ${ }^{15}$ and study challenges could be noted. Chhetri et $\mathrm{al}^{16}$ found out that studies and the concern about not getting enough qualification during remote education could affect students' chances to find a job after graduation and could be indicated as sources of stress for Indian students. In Turkey, a study conducted by Aslan $^{15}$ revealed that students' well-being and stress are influenced by unemployment of a family member, illness and even death of relatives, acting as the main sources of worries. Academic, financial, and social difficulties and lack of interpersonal communication were revealed as the main source of stress in Saudi Arabia. ${ }^{11}$ Conflicts at home and with neighbors, difficulties in isolating noise inside or outside one's home, a lack of direct outdoor access, increased alcohol and tobacco consumption and the perceived ineffectiveness of the use of media entertainment were risk factors for high stress in France. ${ }^{17}$

Speaking about learning and stress, a failure to adapt to virtual learning assignments, exams, reduced learning time, interpersonal relationships caused stress among students during the COVID-19 lockdown. ${ }^{14,16-18}$ The third group of research is related to problems faced by students in online learning during the lockdown. The feeling of isolation and a lack of a sense of community are reported as challenges in online learning environments. ${ }^{19,20}$ These issues became even more important at the time of lockdown. Sufficient home resources facilitating online learning or stable Internet connection were highlighted as the main challenges for their online learning in Saudi Arabia. ${ }^{11}$ A study conducted in Bangladesh highlighted that only $30 \%$ of students from public universities could attend online classes due to poor Internet connectivity and lack of money to buy Internet data in comparison with $76 \%$ of students from private universities. ${ }^{21}$ However, not just technology problems but abilities to work with them could be highlighted. For example, students' ability to deal with technology was highlighted among other challenges in Saudi Arabia. ${ }^{11}$ Moreover, research conducted on a sample of 200 students in Poland showed that students in particular were concerned that online learning would affect class-related issues, such as too much material for self-study, insufficient time to write final papers, or disruption of the course of exams. ${ }^{5}$ Another study showed that perceived usefulness, computer self-efficacy and previous experience have a significant positive influence on students' attitude toward e-learning. ${ }^{22}$ A study by Mishra et $\mathrm{al}^{23}$ at a university in India proved that although online learning during the pandemic was a new experience for students and they felt stressed, they appreciated the initiative taken by the university administration regarding online counselling services for their well-being.

Fourthly, health problem issues were analyzed. A younger age, a lower educational grade, urban residence, living with family/parents, and having children in the family were found as risk factors for mental problems in Bangladesh. ${ }^{24}$ Increased alcohol and tobacco consumption, lack of physical exercise, more Internet browsing time, shifts in eating habits, less exposure to sunlight and dissatisfaction with sleep behavior were also observed during the COVID-19 pandemic ${ }^{16,17,24}$ and can be reasons for negative psychological effects during the lockdown, such as stress, fear, worries, anxiety and depression, which are also the main threats to well-being. ${ }^{8,17,25-28}$

The fifth group of studies is related to burnout. Higher levels of burnout were revealed among students due to self-evaluation, perfectionism, lack of organizational support, lack of academic self-efficacy and lack of teacher support. ${ }^{18}$ However, some contradictory results were found. For example, increased burnout and decreased engagement during online learning were identified by 
Dental Medicine students at Harvard School, ${ }^{29}$ but a study by Bolatov et $\mathrm{al}^{30}$ revealed that burnout, anxiety and depression symptoms decreased when medical students moved from traditional to online learning during the COVID-19 lockdown in Kazakhstan.

The studies conducted for students in the COVID-19 context point to the lack of research connecting students' online learning issues with their stress, burnout and well-being. Moreover, there is some difference in terms of exploring stress and well-being of students in different countries. The authors propose that online learning challenges could relate to students' digital competence, which could be defined as

a set of basic knowledge, skills, abilities, and other characteristics that enable people at work to efficiently and successfully accomplish their job tasks regarding digital media at work. $^{31}$

This idea could be supported by studies conducted before COVID-19, which confirmed that anxiety related to the use of Information Technology (IT) has become widespread in academia $^{32}$ and education-related stress increased when students had to use IT and spend time on it. ${ }^{33}$ In addition, Biggins et $\mathrm{al}^{34}$ and Hefner and Vorderer ${ }^{35}$ highlight a research gap in the analysis of digital stress in higher education environment, and Colás-Bravo et $\mathrm{al}^{36}$ stress the importance of socio-cultural issues in the development of digital competence.

Therefore, there is a gap in the knowledge of the role digital competence plays for students studying online during the COVID-19 pandemic. Therefore, the authors seek to answer the following questions: 1) How did students' digital competence influence their stress, burnout and well-being while studying online during the 2020 lockdown? And 2) Does this influence differ in different countries? This paper focuses on digital competence of students and its influence on perceived stress, burnout and well-being when they moved to online learning because of COVID-19, and offers a comparison of the influence across different countries.

\section{Theoretical Background and Hypotheses}

\section{Relationship Between Well-Being, Stress and Burnout in Higher Education and COVID-19 Pandemic}

Subjective well-being of a person includes emotional wellbeing, which involves life satisfaction and a balance between the positive and negative effect, and positive functioning described by social well-being and psychological well-being. ${ }^{37,38}$ The COVID-19 pandemic influenced changes of well-being giving negative effects and bringing new factors influencing the well-being of students in different countries. Economic problems, the fear of infections and negative information in social media during the lockdown were identified as the main reasons for lower satisfaction and well-being among students. ${ }^{15}$ For example, Aslan ${ }^{15}$ and Jackman et $\mathrm{al}^{39}$ found that students living in rural places have worse life conditions, and the study of Han et $\mathrm{al}^{40}$ points to significantly more severe anxiety among urban college students.

The previous studies revealed that well-being is linked with stress. ${ }^{41}$ As already noted in the Introduction, higher levels of stress could be seen among university students during the COVID-19 pandemic , $^{8,11-13}$ and increased stress was related to changes and concerns of learning during the lockdown, ${ }^{14,16-18}$ when online learning became an additional stressor. Therefore, the authors put forward the following hypotheses:

$\mathrm{H}_{1}$ : Stress experienced during the transition from direct to virtual learning due to COVID-19 is linked with students' subjective well-being.

As studies show, ${ }^{24,42}$ emotionally drained and less satisfied students can experience a high level of stress, which can result in burnout, and could lead to depression and even suicide. Higher stress levels and dissatisfaction are the main reasons of burnout, ${ }^{43,44}$ which could be defined as a syndrome of psychological problems experienced as a result of chronic work-related stress. ${ }^{45}$ Aslan and Bektaş ${ }^{46}$ highlight severe and emotional exhaustion without finding energy and strength to complete the day, desensitization developing insensitivity to illness or prevention, becoming indifferent about taking care of oneself and others, and becoming easily angry as the main indicators of the burnout syndrome.

Depression, permanent hopelessness, tiredness, insomnia, indifference towards rules and duties, lack of interest, negative criticism attitude, devaluation, low achievement and motivation, unwillingness, inability to concentrate on work, decreased sense of control and not believing in finishing school were signs of burnout during COVID-19. ${ }^{47-50}$ Moreover, academic workloads and intense competitive pressure affect students' learning process and academic performance. Therefore, students skip classes, lose attention during the class. This increased academic burnout ${ }^{50-52}$ and could negatively influence their well-being. Studies conducted before COVID-19 
revealed the relationship between burnout and wellbeing. ${ }^{45,53}$ Taking into account that stress is one of the main reasons of burnout, $^{24,42-44}$, and that burnout is linked with well-being, ${ }^{45,53}$ as well as that the transition to online studies during the lockdown became an additional stressor, ${ }^{14,16-18,23}$ the authors propose:

$\mathrm{H}_{2}$ : Stress experienced during the transition from direct to virtual learning due to COVID-19 increases students' burnout.

$\mathrm{H}_{3}$ : Students' burnout experienced during the transition from direct to virtual learning due to COVID-19 is linked with subjective well-being.

\section{The Role of Digital Competence During COVID-19}

Studies on education and stress mostly focus on selfefficacy $^{54,55}$ and self-directed learning. ${ }^{56,57}$ Choi, ${ }^{56}$ based on previous studies, highlighted that academic burnout or stress is a significant predictor in predicting self-directed learning readiness. According to Bolivar, ${ }^{58}$ the concept of competency is linked to the principle of "learning to learn", which is very important in online learning. Moreover, speaking about stress and digital competencies in education, it can be highlighted that these aspects were analyzed more from educators' and not students' perspective. ${ }^{59}$ However, it should be borne in mind that if digital technologies are used without attention to human and environmental health, it could become a source of stress and concern among teachers and students alike. ${ }^{34}$

Carretero et $\mathrm{al}^{60}$ note that according to the European Commission, digital competence includes competencies related to the knowledge and the usage of information, communication and collaboration, the creation of digital content, safety and problem-solving. Marza and $\mathrm{Cruz}^{61}$ highlight digital competence as a useful instrument. It helps students to acquire skills to facilitate the transfer of knowledge and generate innovation while bringing closed attitudes, knowledge and processes related to Information and Communication Technologies (ICT). Therefore, when students have developed digital competence, they can handle technology-related stress. It relates with the statement by Rodgers et $a^{62}$ that technology plays a critical role in managing stress. These issues became essential during the transition to online learning in the COVID-19 pandemic.
There are different classifications of digital competence. However, probably one of the best known is The European Digital Competence Framework for Citizens (DigComp $2.0),{ }^{63}$ provided by the European Commission and including five groups of competencies, where Desjardins ${ }^{64}$ distinguishes three types of digital competence, namely (1) Social (transmit), (2) Informational (store) and (3) Epistemological (process). Social competencies could be described as effective digital communication, collaboration and publication. Informational competencies relate to effective information searching, its evaluation and synthesis, and the production of new knowledge, and Epistemological competencies relate to effective data analysis, problem solving and hypothesis development. ${ }^{64}$

Song et $\mathrm{al}^{65}$ note that it is important to minimize technical problems as much as possible from the beginning of the learning experience. According to Alvarez et al, ${ }^{66}$ the development of digital competence is very important as they will help to adapt to the impact that technology has and to decrease technology-related stress. Therefore, the authors hypothesize:

$\mathrm{H}_{4 \mathrm{~A}}$ : Digital competence of students decreases their experienced stress during the transition from direct to virtual learning due to COVID-19.

Bearing in mind that stress related to digital technologies has been explored within the research on well-being in the work environment ${ }^{67}$ and in home environment ${ }^{68}$ before the COVID-19 pandemic, the authors propose the following:

$\mathrm{H}_{4 \mathrm{~B}}$ : Digital competence of students decreases their burnout during the transition from direct to virtual learning due to COVID-19.

$\mathrm{H}_{4 \mathrm{C}}$ : Digital competence of students increases their wellbeing during the transition from direct to virtual learning due to COVID-19

Summarizing the analysis of studies on well-being, stress, burnout and digital competencies in the current research context, the authors developed a conceptual model (see Figure 1).

\section{Method}

\section{Research Design and Context}

Blayone et al $^{69}$ highlight that readiness for digital learning is an international research domain addressing factors influencing successful technology-enriched education. Moreover, studies on students' stress and well-being 


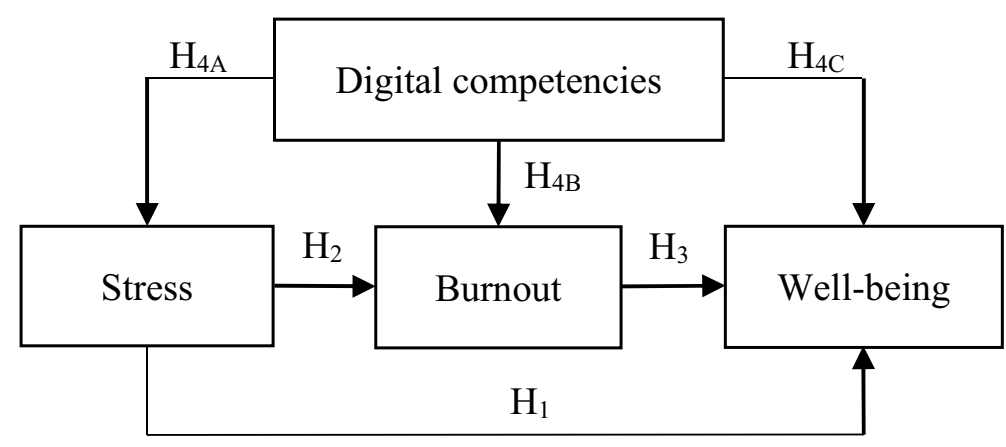

Figure I Conceptual model.

during COVID-19 revealed some differences depending on countries. Therefore, they presuppose the idea to explore the influence of digital competencies on stress, burnout and well-being in different countries.

The authors applied a cross-sectional research design for four selected countries: Poland, Lithuania, Turkey and India to reach the aim. All these countries are different in their size, development and Internet access. Lithuania and Poland are European Union (EU) members who joined the Union in 2004, Turkey is located in Europe and Asia, and India is in Asia. The population is $1,380 \mathrm{~m}$ in India, $84.3 \mathrm{~m}$ in Turkey, $37.8 \mathrm{~m}$ in Poland, and just $2.7 \mathrm{~m}$ in Lithuania. ${ }^{70}$ Looking at individuals using the Internet as a percentage value of population per country, the numbers were as follows $-74 \%$ in Turkey, $82 \%$ in Lithuania and $85 \%$ in Poland in $2019^{71}$ and $50 \%$ in India in $2020 .^{72}$ Evaluating Internet speed per country, Lithuania ranked 31 for fixed Broadband and 34 for Mobile Internet in the world. Accordingly, Poland was 32 and 49, Turkey -103 and 57 and India -65 and 131 in $2021 .^{73}$ The Higher Education Enrollment ratio was also taken into account, which is the ratio of total enrolment, regardless of age, to the population of the age group that officially corresponds to the level of education shown. ${ }^{74}$ According to this ratio, Lithuania with $72.42 \%$ and Poland with $67.83 \%$ are the most educated followed by India $-28.06 \%$ and Turkey $23.86 \%$.

Furthermore, the authors briefly presented the COVID-19 situation, lockdown, and transfer to online learning in the selected countries. Though onset dates and the spread of virus were different in these countries, they all went into lockdown, where all factories, schools, colleges, offices and transportation services were closed, while only essential services such as supermarkets and pharmacies remained open.

\section{Lithuania}

The first case of COVID-19 was reported at 4 a.m. on 28th February 2020 . There were eight cases in Lithuania by the end of 14th March and the government decided to introduce a lockdown from 16th March 2020. It continued for two months. On 16th March, educational institutions in the country were closed and studies moved to virtual platforms. In the majority of cases, institutions did not have any previous experience of teaching online. There was one - during two weeks of Easter holidays, where students and educators participated in online training, webinars, and virtual consultations to learn, prepare and be ready to work online. Institutions prepared lists of necessary equipment for teaching and learning online and in some universities support was provided for both parts. After that, the teaching and learning process took place only online using Zoom, MS-Teams, Adobe Connect, Big Blue Bottom, and so on, and exams were held online too.

\section{Poland}

The first case of COVID-19 coronavirus infection in Poland was reported on 4 March 2020. On 11th March, the number of cases increased to 31 . On that day, the Polish government decided to close educational institutions and universities. Due to the suspension of regular teaching activities, universities began to prepare for online teaching. Some universities immediately, to a limited extent, switched to such a system, some began to gradually introduce online learning. The Ministry of Science issued an ordinance allowing for the replacement of traditional teaching with remote classes. At the same time, it was announced that it would be possible to provide financial support to those universities that were able to quickly launch distance learning platforms. Recommendations, among other things, involved the use of the Navoica educational platform offering Massive Open Online Courses (MOOC) and e-resources owned by universities to provide selected online courses and e-materials in an open formula. The remote teaching system at universities also included practical classes. Until the end of the 2019- 
20 academic year, universities in Poland conducted only online teaching.

\section{Turkey}

The first confirmed case of COVID-19 in Turkey was reported just on 10th March 2020. The Turkish government adopted various restriction measures, such as maintaining social distance, the travel ban on visitors from high-risk countries and quarantine for citizens returning from these countries, followed by closure of schools, shops and entertainment venues. ${ }^{75}$ Distance education was found to be the easiest and most feasible solution for ensuring the sustainability of education in relation to the virus spread all over the world. ${ }^{76}$ Therefore, the Presidency of Turkey announced full remote education of the 2020 spring semester starting in March 2020. Many higher education institutions applied part of materials of a few universities (like Anadolu University and Atatürk University) that had been providing online education for a long time. The students were not familiar with online education, and MS-Teams had been used partly by some teachers. Mainly emails were used to communicate with students for sharing educational material. Students had to self-study during the 2020 spring semester. Exams were taken at home, and answer scripts were sent by emails to professors in the majority of cases.

\section{India}

The first confirmed case of coronavirus infection was reported on 30th January 2020. Initially, a nation-wide curfew was declared on 22nd March. This curfew served as a precursor to the nationwide 21-day lockdown, which was announced at a short notice on 26th March to curb the spread of the coronavirus pandemic. India had approximately 500 confirmed coronavirus cases when the nationwide lockdown was put in place. The lockdown continued in 4 phases until 31st May and then gradual unlocking took place in phases over the following months.

The lockdown disrupted the education sector in India by confining about 320 million students at different levels of education to their homes. Within a week upon the enforcement of lockdown, teachers and students transitioned to virtual teaching and learning without proper institutional support in most cases, but relying on their individual ingenuity. The transition was abrupt and without any preparation time since the academic calendar in India runs from May/June and closes by April/May. Formal institutional training and support were made available gradually to educators. While the Governmentinitiated MOOCs platform (Swayam), an educational portal with curriculum-based, interactive e-content and about 32 direct-to-home (D2H) television channels, were already in place, the provision for optional and supplementary online learning was available to a certain extent, but not as a substitute for regular offline classroom-based learning. Live teacher-student interaction in a virtual classroom, hands-on experience on LMS, such as MS-Teams and Google Classroom, and the generation and distribution of e-content became a new experience for most educators. In India, being a large country with a wide economic disparity, inclusive online education was the biggest challenge as students faced varying levels of access and connectivity to the Internet. During the delayed and shortened summer vacation period for students, several formal online training programs were conducted to equip teachers for online teaching. The default offline face-to-face meeting between teachers and students has not been resumed yet, except in certain cases, such as professional education.

\section{Measures}

Well-being was measured according to the World Health Organization (WHO) Well-being Index. ${ }^{77}$ It measures the subjective well-being of a person during a two-week period and has five statements. The respondents were asked to respond to each statement according to their overall feeling during the whole period of full online distance learning. Statements such as the following were formulated: "I feel/ felt active and vigorous", "My daily life is/was filled with things that interest me". The Cronbach's Alpha score for wellbeing was 0.898 .

Burnout was evaluated using the Copenhagen Burnout inventory. ${ }^{45}$ It incorporated nine statements closely related to students, from the original instrument of 19 questions. Moreover, the authors reformulated questions to statements and used a five-point scale for measurement. The same procedure was followed throughout the whole questionnaire with most of the statements focusing on online learning. Some examples of these statements are: "I often feel tired", "I often think: I can't take it anymore" and "I am tired of classes and consultations with teachers because of the distance mode". The Cronbach's Alpha score here was 0.936 .

\section{Stress}

The authors used the shortened Psychological stress measure (PSM-9) instrument proposed by Lemyre and Tessier $^{78}$ and 
provided six statements focusing on the impact of stress on health, such as "I have pains of sore back" and "I feel preoccupied, tormented, or worried". The Cronbach's Alpha score was 0.873 . A five-point scale from 1 (strongly disagree) to 5 (strongly agree) was used for all the above mentioned (well-being, burnout and stress) measurements.

\section{Digital Competence}

Blayone, ${ }^{79}$ after analyzing scientific literature, compared ten digital competence factors in readiness instruments proposed and used in different countries. The author revealed that the General Technology Competency and Use (GTCU) framework, authored by Desjardins, ${ }^{80}$ is the best and the most representative. The GTCU framework is operationalized using a self-report instrument designed to study the digital abilities of educators and students in higher education. ${ }^{81}$ Freely available, the Digital Competency Profiler (DCP) incorporates this instrument. Moreover, the DCP is being adapted for non-Western contexts of use. ${ }^{79}$

Therefore, digital competence in this study was measured using the DCP list. The authors took the item list provided by Blayone et $\mathrm{al}^{79}$ and tested for onlinelearning activity. Competencies were divided into three groups, where students were asked to rate their current readiness to use technology in online distance learning on a five-point Likert scale, where 1 represents 'not ready at all' and 5 represents "very ready'. In addition, an option "not applicable" was added. Social competence was measured using seven statements (for example, "To communicate with others using text messaging like SMS, Facebook Messenger and so on"). Informational competence includes six statements (for example, "To search for online resources and use them in distance learning as PDF, eBooks, audio"). Epistemological competence has five statements (for example, "To generate concept maps and mind maps using Cmap, xMind, MindMap, MindMeister, Visio and so on"). The Cronbach Alpha of subscales ranged between 0.794 and 0.823 and reached 0.888 for the whole scale of digital competence.

\section{Sampling}

The total sample consisted of four subsamples from selected countriesin particular, Lithuania, Poland, Turkey, and India. A convenient sampling method was employed, which involved contacting students in each country by email, using institutional infrastructure, and inviting them to participate in the research. The Polish subsample size was 130 respondents, while Turkish and Indian subsamples were 107 and 92 respondents, respectively. The participation scale of students from Lithuania was much higher than from other three countries. A total of 768 students participated in the survey and 603 of them filled in the questionnaire. The authors applied a random procedure to get a $20 \%$ of records (131 respondents) for the final subsample of Lithuanian data to keep subsamples by countries of a similar size. Hence, the total sample size used for the analysis was 460 respondents. The characteristics of the sample are presented in Table 1 .

The majority of respondents were females, except in the case of India. About 2.7\% of the respondents from Poland selected "other" for their gender. Regarding institutions, some respondents in Lithuania, Poland, and Turkey were from colleges, universities of applied science, or other institutions of higher education. In case of India, the part of postgraduate/doctoral students was $38.5 \%$ of the sample. Sample characteristics regarding the study field were limited to the number of respondents who reported it. Social Science and Business was the main study field of the respondents from Lithuania, Turkey and India, while Technology Science was the major of respondents from Poland. The same number of respondents in Lithuania were Humanities students. The second largest part of respondents from other countries varied in their fields of study, mainly, Medicine and

Table I Demographic Characteristics of the Sample

\begin{tabular}{|l|c|c|c|c|}
\hline \multirow{2}{*}{ Variables } & \multicolumn{3}{|c|}{ Countries } \\
\cline { 2 - 5 } & & Lithuania (I) & Poland (2) & Turkey (3) \\
\hline Gender (female: N, \%) & $83(79)$ & $56(50.9)$ & $64(59.8)$ \\
Age (mean) & 25.38 & 23.08 & 23.33 \\
Institution (University: N, \%) & $98(91.6)$ & $108(99.1)$ & $90(84.1)$ \\
Study level (undergraduates: N, \%) & $83(77.6)$ & $64(71.1)$ & $99(92.5)$ \\
N & 131 & 130 & $39(100)$ & 107 \\
\hline
\end{tabular}


Table 2 Descriptive and Correlation Matrix

\begin{tabular}{|c|c|c|c|c|c|c|c|c|c|}
\hline \multirow[t]{2}{*}{ Main Variables } & \multirow[t]{2}{*}{$\mathbf{N}$} & \multirow[t]{2}{*}{ Mean } & \multirow[t]{2}{*}{ SD } & \multicolumn{6}{|c|}{ Correlation Coefficient } \\
\hline & & & & DC & $\begin{array}{l}\text { Social } \\
\text { DC }\end{array}$ & $\begin{array}{c}\text { Informational } \\
\text { DC }\end{array}$ & $\begin{array}{c}\text { Epistemological } \\
\text { DC }\end{array}$ & $\begin{array}{l}\text { Well- } \\
\text { Being }\end{array}$ & Stress \\
\hline $\begin{array}{l}\text { Digital competence } \\
\text { (DC) }\end{array}$ & 440 & 3.27 & 0.9383 & & & & & & \\
\hline Social DC & 439 & 3.60 & 1.0233 & $0.628 * *$ & & & & & \\
\hline Informational DC & 440 & 3.48 & $1.07 \mid 1$ & $0.724 * *$ & $0.499 * *$ & & & & \\
\hline Epistemological DC & 437 & 2.56 & 1.2482 & $0.610 * *$ & $0.263 * *$ & $0.425 * *$ & & & \\
\hline Well-being & 460 & 2.81 & 0.9569 & $0.230 * *$ & $0.190 * *$ & $0.252 * *$ & $0.173^{* *}$ & & \\
\hline Stress & 460 & 2.95 & 1.0513 & $-0.100 * *$ & $-0.090 * *$ & $-0.107 * *$ & -0.055 & $-0.444 * *$ & \\
\hline Burnout & 460 & 3.15 & 1.0439 & $-0.136 * *$ & $-0.148^{* *}$ & $-0.157 * *$ & $-0.079 *$ & $-0.500 * *$ & $0.58 \mathrm{I} * *$ \\
\hline
\end{tabular}

Notes: Kendall's tau-b correlation coefficient was used; ${ }^{*} \mathrm{p}<0.05$; ${ }^{* *} \mathrm{p}<0.0$ I.

Health Sciences, Technology Science, or Social Science and Humanities.

\section{Data Gathering}

An online survey was used for data collection. A link to the online questionnaire was distributed to the students by email, using institutional infrastructure by the authors of this paper in individual countries covered by the study. The study was conducted in spring 2020, from April till June. Institutions of higher education in selected countries provided online teaching during that period.

\section{Data Analysis}

The data analysis was run with the software IBM SPSS and Smart PLS for Structural Equation Modelling (SEM). SEM was selected because of its ability to estimate direct and indirect relationships among variables. Structural models show dependencies between exogenous (independent, unexplained or unpredicted by other variables) and endogenous (dependent) variables. ${ }^{82}$

\section{Results}

Correlation analysis of digital competence, well-being, stress, and burnout was run for hypotheses testing (see Table 2). The results showed a negative moderate correlation between stress and subjective well-being $(r=-0.444$, $\mathrm{p}<0.001$ ), confirming $\mathrm{H}_{1}$. It was also confirmed that stress and burnout were positively correlated in moderate strength $(\mathrm{r}=0.581, \mathrm{p}<0.001)$, therefore supporting $\mathrm{H}_{2}$. The results also reveal a negative moderate relationship between students' burnout and their subjective well-being $(\mathrm{r}=-0.500, \mathrm{p}<0.001)$, also supporting $\mathrm{H}_{3}$.
The results also point to a positive but weak correlation between digital competencies and well-being $(r=0.230$, $\mathrm{p}<0.001)$. The highest correlation was confirmed in case of informational dimension $(r=0.252, p<0.001)$ and the lowest correlation was found in case of epistemological dimension of digital competencies $(r=0.173, p<0.001)$. In addition, digital competence was negatively and weakly correlated with stress $(\mathrm{r}=-0.100, \mathrm{p}=0.003)$ and burnout $(r=-0.136, p<0.001)$. In case of epistemological dimension of digital competencies, a significant correlation with stress was not found, while a significant negative but very weak correlation was found in relationship with burnout $(\mathrm{r}$ $=-0.079, \mathrm{p}=0.018$ ).

A comparative analysis of digital competence, wellbeing, stress and burnout revealed differences among the selected countries (see Table 3).

The digital competence of students in the subsample of Turkey was ranked the lowest in comparison with students from other countries. The exception was found in case of epistemological dimension of digital competence that was ranked the lowest by the students in the subsample of Lithuania. Lithuanian students also reported lower stress and much lower burnout than students from other countries. Moreover, Lithuanians were found better in the wellbeing situation than other students. The highest stress was found among students in Poland and India in addition to the highest burnout among students in Poland. High levels of stress and burnout were also corresponding to their lowest level of well-being.

SEM was used for testing the influence of students' digital competence on their stress and burnout. The first tested model represented the authors" research model (see 
Table 3 Results Matrix of Multiple Comparison Analysis

\begin{tabular}{|c|c|c|c|c|c|c|c|}
\hline \multirow{3}{*}{$\begin{array}{l}\text { Variables } \\
\text { Digital competence }\end{array}$} & \multicolumn{4}{|c|}{ Countries (Mean Ranks) } & \multirow{2}{*}{\multicolumn{2}{|c|}{ Chi-Square }} & \multirow[t]{3}{*}{ df } \\
\hline & \multirow{2}{*}{$\begin{array}{c}\text { Lithuania } \\
192.00\end{array}$} & \multirow{2}{*}{$\begin{array}{l}\text { Poland } \\
257.31\end{array}$} & \multirow{2}{*}{$\begin{array}{c}\text { Turkey } \\
182.22\end{array}$} & \multirow{2}{*}{$\begin{array}{c}\text { India } \\
254.49\end{array}$} & & & \\
\hline & & & & & 32.432 & $* *$ & \\
\hline Social DC & 258.89 & 252.73 & 149.92 & 207.53 & 53.095 & $* *$ & 3 \\
\hline Informational DC & 209.36 & 261.14 & 172.12 & 238.42 & 30.730 & $* *$ & 3 \\
\hline Epistemological DC & 136.97 & 243.33 & 224.80 & 285.74 & 80.502 & $* *$ & 3 \\
\hline Well-being & 273.39 & 201.35 & 232.95 & 207.77 & 27.706 & $* *$ & 3 \\
\hline Stress & 205.94 & 248.03 & 224.87 & 247.25 & 8.406 & $*$ & 3 \\
\hline Burnout & 166.70 & 264.86 & 249.54 & 250.65 & 43.217 & $* *$ & 3 \\
\hline
\end{tabular}

Notes: Kruskal Wallis test was used; ${ }^{*} \mathrm{p}<0.05$; ${ }^{*} \mathrm{p}<0.01$.

Figure 1). Model 2 included a country as a control variable for measuring its influence on the research model. The results of the tested models are presented in Table 4, providing only significant paths.

SEM results showed no significant influence of digital competence on stress, rejecting $\mathrm{H}_{4 \mathrm{~A}}$. Still, correlation analysis confirmed a weak but significant negative correlation between social and informational dimensions of digital competence and stress (see Table 2), still providing an argument for $\mathrm{H}_{4 \mathrm{~A}}$. Similarly, correlation analysis revealed a weak but significant correlation between social and informational dimensions of digital competence and burnout. However, this time structural equation modelling confirmed the impact of social dimension of digital competence on burnout $(\beta=-0.201, \mathrm{p}<0.001)$, partly confirming $\mathrm{H}_{4 \mathrm{~B}}$.

The results also confirmed the direct influence of informational dimension of digital competence $(\beta=0.150$, $p=0.012)$ and the indirect influence of social dimension of digital competence on well-being $(\beta=0.106, p=0.001)$, mediated by burnout. The impact of both dimensions was positive. The role of burnout in mediation was negative, minimizing a positive influence of social dimension on wellbeing. As far as the impact on well-being, it was found only in case of two dimensions of digital competence, and therefore $\mathrm{H}_{4 \mathrm{C}}$ is also confirmed only partly.

In summary, model 1 confirmed the positive influence of some dimensions of digital competence together with a negative impact of stress and burnout on well-being $\left(\mathrm{R}^{2} \mathrm{adj} .=0.544\right)$ and a positive influence of informational dimension of digital competence with a negative impact of stress on burnout $\left(\mathrm{R}^{2}\right.$ adj. $\left.=0.615\right)$.

Model 2 had a similar good model fit $\chi^{2}=2527.512$, SRMR $=0.074$, NFI $=0.786$, RMS Theta $=0.117)$ as
Table 4 SEM Results on Model Testing

\begin{tabular}{|c|c|c|c|c|}
\hline & \multicolumn{2}{|c|}{ Model I } & \multicolumn{2}{|c|}{ Model 2} \\
\hline \multicolumn{5}{|c|}{ Independent variables (Path coefficients) } \\
\hline Social DC > Burnout & -0.201 & $(<0.001)$ & -0.136 & $(0.012)$ \\
\hline Burnout $>$ Well-being & -0.529 & $(<0.001)$ & -0.552 & $(<0.001)$ \\
\hline Informational DC > Well-being & 0.150 & $(0.012)$ & 0.172 & $(0.005)$ \\
\hline Stress $>$ Burnout & 0.749 & $(<0.00 I)$ & 0.736 & $(<0.001)$ \\
\hline Stress $>$ Well-being & -0.143 & $(0.027)$ & -0.135 & $(0.04 I)$ \\
\hline \multicolumn{5}{|c|}{ Control Variable (Path coefficients) } \\
\hline Country > Social DC & & & -0.258 & $(<0.001)$ \\
\hline Country > Epistemological DC & & & 0.374 & $(<0.001)$ \\
\hline Country > Well-being & & & 0.084 & $(0.025)$ \\
\hline Country $>$ Stress & & & 0.153 & $(0.006)$ \\
\hline Country > Burnout & & & 0.145 & $(<0.001)$ \\
\hline \multicolumn{5}{|l|}{ Dependent variables ( $R^{2}$ adj.) } \\
\hline Well-being & \multicolumn{2}{|c|}{0.544} & \multicolumn{2}{|c|}{0.546} \\
\hline Stress & \multicolumn{2}{|c|}{0.008} & \multicolumn{2}{|c|}{0.022} \\
\hline Burnout & \multicolumn{2}{|c|}{0.615} & \multicolumn{2}{|c|}{0.629} \\
\hline SRMR & \multicolumn{2}{|c|}{0.07} & \multicolumn{2}{|c|}{0.074} \\
\hline Chi-square & \multicolumn{2}{|c|}{2460.22} & \multicolumn{2}{|c|}{2527.512} \\
\hline NFI & \multicolumn{2}{|c|}{0.787} & \multicolumn{2}{|c|}{0.786} \\
\hline rms Theta & \multicolumn{2}{|c|}{0.119} & \multicolumn{2}{|c|}{0.117} \\
\hline
\end{tabular}

model $1\left(\chi^{2}=2460.22\right.$, SRMR $=0.070$, NFI $=0.787$, RMS Theta $=0.119)$ and provided an additional confirmation of the tested research model, revealing the influence of a country (Figure 2).

The country influenced social and epistemological dimensions of digital competence, as well as stress, burnout and well-being of students, responding positively to the second research question if there is any difference of this effect in different countries. The general influence on 


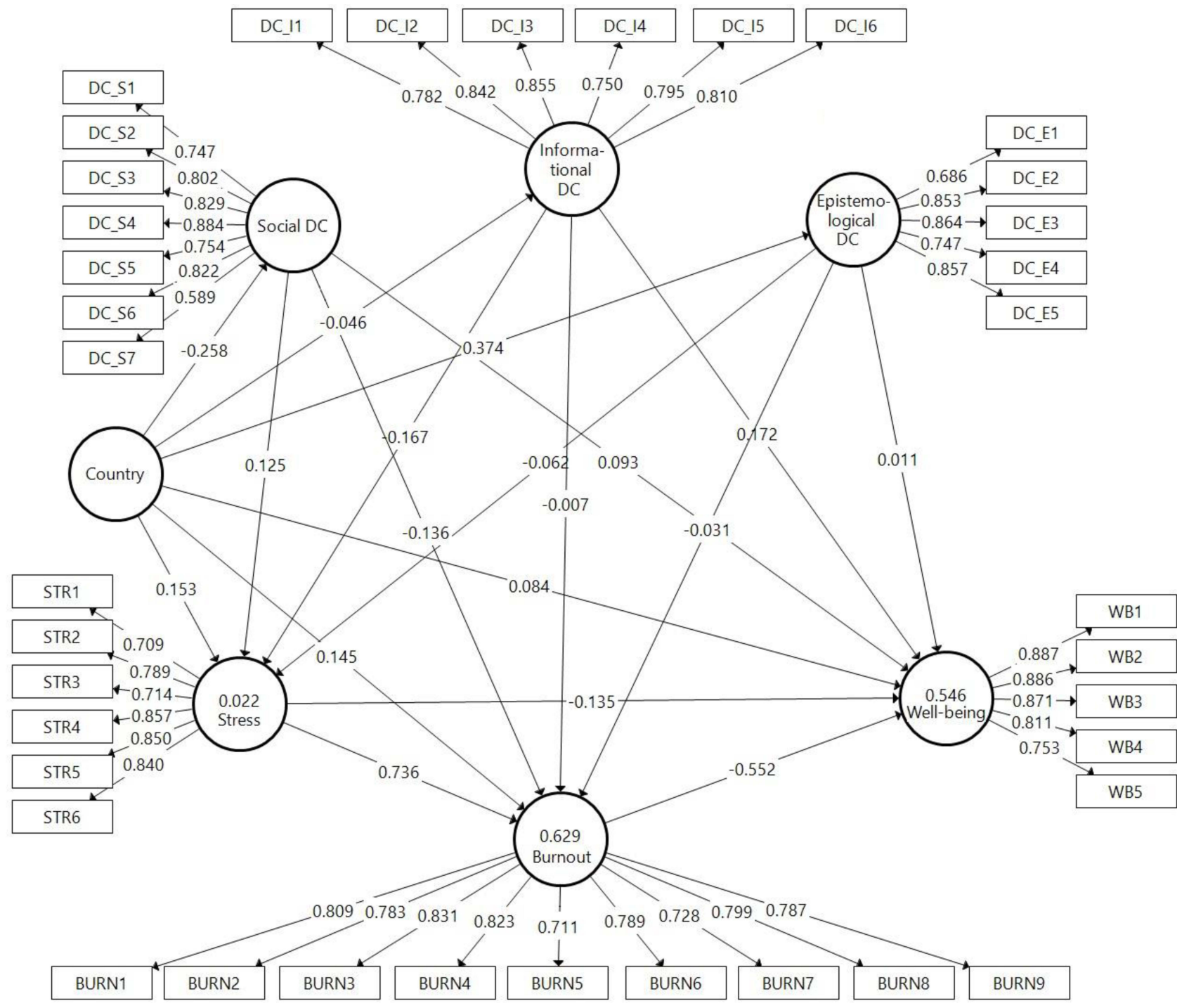

Figure 2 Final model.

Notes: Item loadings are presented for outer model. Path coefficients are presented for inner model. $\mathrm{R}^{2}$ adj. is presented for stress, burnout, and well-being.

burnout $\left(\mathrm{R}^{2}\right.$ adj. $\left.=0.629\right)$ and well-being $\left(\mathrm{R}^{2} \mathrm{adj} .=0.546\right)$ is slightly higher. In addition, SEM was run for each country separately to evaluate the impact of digital competence on stress, burnout, and well-being of students in each country. The Lithuanian results mainly confirmed the influence of epistemological dimension of digital competence on stress $(\beta=-0.226, p=0.033)$ and specific indirect effect on burnout $(\beta=-0.202, p=0.033)$. Its total influence on burnout was slightly higher $(\beta=-0.228$, $\mathrm{p}=0.030$ ). Its positive total influence on well-being was also identified $(\beta=0.237, p=0.015)$. Meanwhile, the Polish results confirmed the influence of informational dimension of digital competence on stress $(\beta=-0.303$, $\mathrm{p}=0.007)$, its total indirect negative effect on burnout ( $\beta=$ $-0.257, p=0.008$ ) and a total indirect positive effect on well-being $(\beta=0.208, p=0.010)$. The results of the Turkish sample showed only the influence of social dimension of digital competence on burnout $(\beta=-0.313$, $\mathrm{p}=0.049$ ). The results of the Indian sample confirmed the influence of epistemological dimension of digital competence on well-being only, in the ways of $\operatorname{direct}(\beta=$ $0.237, \mathrm{p}=0.025)$ and total effects $(\beta=0.315, \mathrm{p}=0.013)$. All SEM models for each country lacked a goodness of fit. Nonetheless, they all confirmed that stress increased the burnout effect and both of them deteriorated the wellbeing of students.

\section{Discussion}

The COVID-19 pandemic put online teaching and learning under a stress-test that accelerated the digitalization of 
higher education teaching. ${ }^{83}$ This situation surprised the higher education system in all countries and was a challenge not only for teachers but also for students. The research conducted for the purpose of this article revealed the existence of a negative correlation between stress and subjective well-being among students $\left(\mathrm{H}_{1}\right)$ who, due to the COVID-19 pandemic, started remote education in spring 2020. This result is consistent with the findings of related studies carried out by other authors among students in different countries. ${ }^{9-14}$ This study also confirmed that stress experienced by students and their burnout during the transition from direct to online learning were positively correlated $\left(\mathrm{H}_{2}\right)$. Such a correlation also appeared in the studies by Aslan et al, ${ }^{13}$ and Abram and Jacobowitz. ${ }^{18}$ They found that high stress is the main cause of burnout in the long term. The results of the studies included in this paper also reveal a negative relationship between students' burnout and their subjective well-being $\left(\mathrm{H}_{3}\right)$ in the process of adaptation to distance learning, hence supporting the findings of Abram and Jacobowitz. $^{18}$

Furthermore, in answering the first research question How did students' digital competence influence their stress, burnout and well-being while studying online during the 2020 lockdown? - some interesting insights could be provided. A negative correlation was found between social and informational dimensions of digital competencies and stress $\left(\mathrm{H}_{4 \mathrm{~A}}\right)$. However, SEM results did not show any significant results, demanding deeper explorations in this field. The correlations revealed in the presented research are in line with the previously conducted study by Alvarez et al, ${ }^{66}$ who emphasized that digital competence could lower technology-related stress. Similar results were revealed concerning burnout. Digital competence was negatively correlated with burnout and structural equation modelling confirmed the influence of social dimension of digital competence on burnout, partly confirming $\mathrm{H}_{4 \mathrm{~B}}$.

Moreover, differences were identified between the level of correlation of each of the three dimensions of digital competence (informational, social and epistemological) of students and their well-being. The informational dimension of digital competence had the highest, and the epistemological dimension - the lowest correlations. SEM results confirmed the direct influence of informational dimension of digital competence and the indirect impact of social dimension of digital competence on well-being, mediated by burnout. As just two dimensions had statistical significance, $\mathrm{H}_{4 \mathrm{C}}$ is also confirmed only partly. Looking at previous studies by Liang and Hsieh, ${ }^{84}$ and Thomas and Lankau, ${ }^{85}$ it could be stated that supportive communication and socialization decrease burnout and their importance remain not only in physical but also in online communication too, as it was found in this study.

Pertaining to the second question - Does the influence of students' digital competence on stress, burnout and wellbeing while studying online during the 2020 lockdown differ in different countries? - the results confirmed the influence of a country in terms of the impact of digital competence on stress, burnout, and well-being. A comparison analysis of digital competence, well-being, stress and burnout revealed differences among countries covered by this study. Firstly, the authors would like to note that the lowest stress is identified among Lithuanian students, also reflecting the lowest burnout and better wellbeing situation than in case of students from other countries, and the highest stress level was found among the students in Poland and India, also revealing the high level of stress and burnout as well as the lower level of well-being. Such results could be related to the pandemic situation, the nature of lockdown restrictions and Internet infrastructure and penetration in the explored countries. However, this paper is not focused on investigating in this aspect.

SEM results showed that the epistemological dimension of digital competence (ability to use digital time planning tools, to create and analyze data, to develop online content, to generate concept and mind maps) was scored by Indian students at the highest and by Lithuanians at the lowest in comparison to the students from other countries and among other competence dimensions inside Lithuania. For Indian students, the positive influence of epistemological dimension just on well-being was found. Considering the fact that more respondents from India were postgraduates in the sample, the importance of epistemological dimension of digital competence is higher for them than for undergraduate students and its usage influenced their well-being. This corresponds with the previous study of Aslan et $\mathrm{al}^{13}$ claiming that undergraduate students felt higher stress than postgraduates. In case of Lithuania, as this was evaluated the worst, students having better epistemological dimension seemed to deal better with stress and burnout and to improve their wellbeing. However, all these insights need deeper analysis.

For Polish students, not epistemological but informational dimension (abilities to search for necessary information online and to use it in digital learning) was 
evaluated the highest in the country and among other countries and contributed to the lower level of stress and burnout as well as to the higher level of well-being. Regarding Turkish students, their social dimension of digital competence helped them to deal with burnout, although it was the lowest scored dimension among Turkish students as well as among other countries. Looking at the subsample of Turkey, it should be remembered that the vast majority of respondents were undergraduates and that studies were mostly delivered individually with material shared using e-mail - not through online platforms. However, following the previous study by Aslan et $\mathrm{al}^{13}$ it can be stated that undergraduate students pointed to the loss of face-to-face contact with friends as one of the main challenges. The ability to communicate using various online tools, social network systems and online collaboration platforms contributed to the lower level of burnout for Turkish students.

\section{Limitations and Further Research Suggestions}

Firstly, convenient sampling was selected for this study, and all the variables were self-reported by the participants, which may have resulted in a common method bias. ${ }^{86}$ Therefore, for future research seeking to replicate and expand the findings, the authors propose collecting data from multiple sources to further reduce the likelihood of a common method bias.

Secondly, the authors did not explore students' previous experience in studying virtually and the involvement of their institutions' in this process before the lockdown. Nor did they compare changes in well-being and digital competence while working physically and online as this was not an aim of this study. However, future research could focus on the comparison of well-being and digital competencies before studies online and in their course.

Thirdly, the cross-sectional design of this study precludes drawing conclusions regarding causality or temporal precedence. Therefore, research exploring how digital competencies change during recurrent lockdown period(s) and the return to a "normal" by conducting a longitudinal study should be advised.

Fourthly, the conceptual model was confirmed, but SEM results for each country have some limitations due to the lack of goodness-of-fit. Each country dealt with lockdown and online learning differently. Therefore, additional and different factors played their roles in a particular country, which were not explored in the current study but could be involved in further studies.

Fifthly, some controversial results among the dimensions of digital competence dimensions and their influence in different countries were found, posing additional questions which the current study could not answer. This could relate to particular education systems, different teaching and learning methods, requirements and study programs in different countries, which were not explored in this study and, therefore, offer further research directions.

Sixthly, this study was more of the exploratory nature, focusing on digital competence as specific phenomenon influence on stress, burnout and well-being of students in different countries. However, the authors focused just on particular four countries, trying to explore their primary assumptions and did not compare the results in relation to demographic characteristics. Therefore, future research should consider examining (i) how digital competencies differ between undergraduates and postgraduates, (ii) how digital competencies influence well-being and stress of students in other countries, and (iii) how digital competencies and well-being differ among students in relation to their field of studies, (vi) what are other factors of digital learning environment that are related with digital competencies in different countries and influence well-being in online learning.

Finally, because of the exploratory nature of this research and situational constraints, as well as considering time and cost matters, the authors focused only on the digital competence role for students' stress, burnout and well-being in a particular period, not trying to contribute to a specific theory. However, future studies could include social support aspects contributing to the social support theory.

\section{Theoretical Contributions}

The findings presented in the paper add to the existing knowledge about the links between the level of digital competencies and students' feeling in terms of wellbeing, stress and burnout in the transition from direct to virtual learning due to COVID-19. They fill a research gap identified by Biggins et $\mathrm{al}^{34}$ and Hefner and Vorderer ${ }^{35}$ concerning the identification of digital stress in higher education. This study has taken a different perspective, focusing on the students and not the teachers, as is the case in most studies on distance learning.

The results of this study provide a number of contributions: (i) they show a direction and the strength of the 
correlation between digital competence and well-being, stress and burnout experienced by students during the period of commencing remote learning as a result of COVID-19 (ii) they show that students' well-being depends on their digital competence, showing that information searching (informational) and communication (social) dimensions of competence are important for students' dealing with stress and burnout, and their wellbeing; this element of the presented findings is an original contribution to expand better understanding of the role of digital competence in online higher education, and (iii) they have an international character and allow for a comparison of the identified links among digital competence, well-being, stress and burnout of students from across countries, showing that these relationships are also linked to the cultural context (as previously pointed out by Colás-Bravo et $\mathrm{al}^{36}$ ).

\section{Practical Recommendations}

The highlighted results could summarize when students have better digital competence, as well as how it may help to decrease stress and burnout and to improve their well-being studying online. Following types of tasks, educators should pay attention what dimension of digital competence is necessary to complete them. It is important to pay attention if students need just to communicate (here social competence is sufficient), or whether they need to find and analyze information, which corresponds with informational competence. Finally, if students need to analyze data and solve problems online, they need epistemological competence. According to the necessity to develop lacking digital competencies, special means and/ or courses could be proposed to be developed for students.

\section{Conclusion}

The findings from the current exploratory study revealed the importance of digital competence among students studying online during the COVID-19 lockdown. This research was conducted at a very important time when the physical closing of educational institutions temporarily enforced a sudden transition that accelerated the digitalization of teaching. ${ }^{83}$

The results showed that social and informational dimensions of digital competencies could decrease stress, and the social dimension could reduce burnout experienced by students studying online. The informational dimension had a direct, and social dimension - indirect, mediated by burnout, influence on well-being of students.
Considering the country-to-country difference, the Lithuanian students demonstrated the lowest, and the Polish and Indian students - the highest stress and burnout among explored countries. The informational dimension in case of Polish and the epistemological dimension in case of Lithuanian students decreased their stress and burnout and positively influenced well-being. Moreover, the epistemological dimension had a positive impact on wellbeing of Indians. Still, the social dimension of digital competence helped Turkish students to deal with burnout. Therefore, such highlighted differences prompt to conduct further studies to explore this phenomenon deeper.

\section{Ethics Statement}

Declaration by authors of the nature of research-ethical issues:

The research does not fall within the field of clinical psychology. Neither is it of a clinical nature. This type of research does not in any way threaten the well-being of the people involved. The respondents participated voluntarily and anonymously, accepting the Participant Agreement, which included the following information "I certify that I am 18 years or older and my participation in this survey is entirely voluntary. I release any claim to collected data, research results, publishing or other non-commercial use of the findings, resulted from the collected information." This study has been conducted following the research ethics and integrity, according to the Code of Academic Ethics, approved by Kaunas University of Technology (KTU) Senate resolution no. V3-S-1 of 25 January, 2012, in particular, part V. "Standards of ethics for researchers". Following the requirements of research ethics at KTU, research team ensured the same standards of research ethics for gathering data in all research countries (Lithuania, Poland, India, and Turkey).

\section{Author Contributions}

All authors made a significant contribution to the work reported, whether that is in the conception, study design, execution, acquisition of data, analysis and interpretation, or in all these areas; took part in drafting, revising or critically reviewing the article; gave final approval of the version to be published; have agreed on the journal to which the article has been submitted; and agree to be accountable for all aspects of the work.

\section{Disclosure}

The authors declare no conflict of interest in this work. 


\section{References}

1. Data.europe.eu [homepage on the Internet]. Education during COVID-19; moving towards e-learning; 2020. Available from: https://data.europa.eu/en/impact-studies/covid-19/education-duringcovid-19-moving-towards-e-learning. Accessed June 19, 2021..

2. Pokhrel S, Chhetri R. A literature review on impact of COVID-19 pandemic on teaching and learning. High Educ Future. 2021;8 (1):133-141. doi:10.1177/2347631120983481

3. Unesco [homepage on the Internet]. School closures caused by Coronavirus (Covid-19); 2020. Available from: https://en.unesco. org/covid19/educationresponse. Accessed June 19, 2021.

4. McVay M. How to Be Successful Distance Learning Student: Learning on the Internet. 2nd ed. Boston: Pearson Custom; 2000.

5. Lis M, Wolna N, Moczulska M, Solińska K. Social aspects of introducing online learning - the students' perspective. e-Mentor. 2020;86(4):36-46. doi:10.15219/em86.1480

6. Korkmaz G, Toraman Ç. Are we ready for the post-COVID-19 educational practice? An investigation into what educators think as to online learning. Int J Technol Educ Sci. 2020;4(4):293-309. doi:10.46328/ijtes.v4i4.110

7. Fujiwara D, Dolan P, Lawton R, et al. The Wellbeing Costs of COVID-19 in the UK; 2021. Available from: https://www.ceci.org.uk/ the-wellbeing-costs-of-covid-19-in-the-uk/. Accessed June 7, 2021.

8. Ahmed O, Ahmed MZ, Alim S, Khan MD, Jobe MC. COVID-19 outbreak in Bangladesh and associated psychological problems: an online survey. Death Stud. 2020;1-10. doi:10.1080/07481187.2020.1818884

9. Li X, Lv Q, Tang W, et al. Psychological stresses among Chinese university students during the COVID-19 epidemic: the effect of early life adversity on emotional distress. $J$ Affect Disord. 2021;1 (282):33-38.

10. Ye B, Wu D, Im H, Liu M, Wang X, Yang Q. Stressors of COVID-19 and stress consequences: the mediating role of rumination and the moderating role of psychological support. Child Youth Serv Rev. 2020;118:105466. doi:10.1016/j.childyouth.2020.105466

11. AlAteeq DA, Aljhani S, AlEesa D. Perceived stress among students in virtual classrooms during the COVID-19 outbreak in KSA. $J$ Taibah Univ Med Sci. 2020;15(5):398-403. doi:10.1016/j. jtumed.2020.07.004

12. Hoyt LT, Cohen AK, Dull B, Castro EM, Yazdani N. "Constant stress has become the new normal": stress and anxiety inequalities among US College students in the time of covid-19. J Adolesc Health. 2021;68(2):270-276. doi:10.1016/j.jadohealth.2020.10.030

13. Aslan I, Ochnik D, Çınar O. Exploring perceived stress among students in Turkey during the COVID-19 pandemic. Int $J$ Environ Res Public Health. 2020;17(23):8961. doi:10.3390/ijerph17238961

14. Thai TT, Le PTV, Huynh QHN, Pham PTT, Bui HTH. Perceived stress and coping strategies during the COVID-19 pandemic among public health and preventive medicine students in Vietnam. Psychol Res Behav Manag. 2021;14:795-804. doi:10.2147/PRBM.S317059

15. Aslan I. Evaluating wellbeing and worries of university students during COVID-19 pandemic. Atatürk Üniversitesi Iktisadi Ve Idari Bilimler Dergisi. 2021;35(1):245-261.

16. Chhetri B, Goyal LM, Mittal M, Battineni G. Estimating the prevalence of stress among Indian students during the COVID-19 pandemic: a cross-sectional study from India. J Taibah Univ Med Sci. 2021;16(2):260-267. doi:10.1016/j.jtumed.2020.12.012

17. Bourion-Bédès $\mathrm{S}$, Tarquinio $\mathrm{C}$, Batt $\mathrm{M}$, et al. Stress and associated factors among French university students under the COVID-19 lockdown: the results of the PIMS-CoV 19 study. J Affect Disord. 2021;283:108-114. doi:10.1016/j.jad.2021.01.041

18. Abram MD, Jacobowitz W. Resilience and burnout in healthcare students and inpatient psychiatric nurses: a between-groups study of two populations. Arch Psychiatr Nurs. 2021;35(1):1-8. doi:10.1016/j. apnu.2020.10.008
19. Petrides LA. Web-based technologies for distributed (or distance) learning: creating learning-centered educational experiences in the higher education classroom. Int J Instr Media. 2002;29(1):69.

20. Woods RH. How much communication is enough in online courses? Exploring the relationship between frequency of instructor-initiated personal email and learners' perceptions of and participation in online learning. Int J Instr Media. 2002;29(4):377-394.

21. Shafiq S, Nipa SN, Sultana S, Rahman UR, Rahman M. Exploring the triggering factors for mental stress of university students amid COVID-19 in Bangladesh: a perception-based study. Child Youth Serv Rev. 2021;120:105789. doi:10.1016/j.childyouth.2020.105789

22. Ejdys J. Factors affecting the adoption of e-learning at university level. WSEAS Trans Bus Econ. 2021;18:313-323. doi:10.37394/ 23207.2021.18.32

23. Mishra L, Gupta T, Shree A. Online teaching-learning in higher education during lockdown period of COVID-19 pandemic. Int J Educ Res. 2020;1:100012. doi:10.1016/j.ijedro.2020.100012

24. Mamun MA, Chandrima RM, Griffiths MD. Mother and son suicide pact due to COVID-19-related online learning issues in Bangladesh: an unusual case report. Int $J$ Ment Health Addict. 2020;1-4. doi:10.1007/s11469-020-00362-5

25. Brown E, Gray R, Monaco SL, et al. The potential impact of COVID-19 on psychosis: a rapid review of contemporary epidemic and pandemic research. Schizophr Res. 2020;222:79-87. doi:10.1016/ j.schres.2020.05.005

26. Jawad H, Qasir H, Iqbal N, Azhar J, Mubeen A, Azhar MA. Wellbeing of veterinary and medical students during COVID-19 pandemic. Acta Sci Vet Sci. 2020;2(7):31-34. doi:10.31080/ASVS.2020.02.0077

27. Razvi SMH, Prasad N. Covid-19 a potential threat? Int J Innov Res Med Sci. 2020;12:1-4.

28. Vieira CM, Franco OH, Restrepo CG, Abel T. COVID-19: the forgotten priorities of the pandemic. Maturitas. 2020;136:38-41. doi:10.1016/j.maturitas.2020.04.004

29. Chen E, Kaczmarek K, Ohyama H. Student perceptions of distance learning strategies during COVID-19. J Dent Educ. 2020. doi: $10.1002 /$ jdd. 12339

30. Bolatov AK, Seisembekov TZ, Askarova AZ, Baikanova RK, Smailova DS, Fabbro E. Online-learning due to COVID-19 improved mental health among medical students. Med Sci Educ. 2021;31 (1):183-192. doi:10.1007/s40670-020-01165-y

31. Oberländer M, Beinicke A, Bipp T. Digital competencies: a review of the literature and applications in the workplace. Comput Educ. 2020;146:103752. doi:10.1016/j.compedu.2019.103752

32. Rahimi M, Yadollahi S. Success in learning English as a foreign language as a predictor of computer anxiety. Procedia Comput Sci. 2011;3:175-182. doi:10.1016/j.procs.2010.12.030

33. Mark G, Wang Y, Niiya M Stress and Multitasking in Everyday College Life: an empirical Study of Online Activity: Proceedings of SIGCHI Conference on Human Factors in Computing Systems (CHI'14), 2014; 41-50.

34. Biggins D, Holley D, Zezulkova M. Digital competence and capability frameworks in higher education: importance of life-long learning, self-development and well-being. EAI Endorsed Trans e-Learn. 2017;4(13):1-7. doi:10.4108/eai.20-6-2017.152742

35. Hefner D, Vorderer P. Digital stress: permanent connectedness and multitasking. In: Reinecke L, Oliver MB, editors. The Routledge Handbook of Media Use and Well-Being. New York: Routledge; 2017:341-354.

36. Colás-Bravo P, Conde-Jiménez J, Reyes-de Cozar S. The development of the digital teaching competence from a sociocultural approach. Comunicar. 2019;27(2):19-30. doi:10.3916/C61-2019-02

37. Keyes CLM, Magyar-Moe JL. The measurement and utility of adult subjective well-being. In: Lopez SJ, Snyder CR, editors. Positive Psychological Assessment: A Handbook of Models and Measures. Washington (DC): American Psychological Association; 2003:411-425. 
38. Keyes CL. Social well-being. Soc Psychol Q. 1998;61(2):121-140. doi: $10.2307 / 2787065$

39. Jackman D, Konkin J, Yonge O, Myrick F, Cockell J. Crisis and continuity: rural health care students respond to the COVID-19 outbreak. Nurse Educ Pract. 2020;48:102892. doi:10.1016/j. nepr.2020.102892

40. Han W, Xu L, Niu A, et al. Online-based survey on college students' anxiety during COVID-19 outbreak. Psychol Res Behav Manag. 2021;14:385-392. doi:10.2147/PRBM.S298539

41. Hart P, Cotton P. Conventional wisdom is often misleading: police stress within an organizational health framework. In: Dollard M, Winefield HR, Winefield AH, editors. Occupational Stress in the Service Professions. London: CRC Press; 2003:103-141.

42. Lathabhavan R, Griffiths M. First case of student suicide in India due to the COVID-19 education crisis: a brief report and preventive measures. Asian J Psychiatr. 2020;53:102202. doi:10.1016/j.ajp.2020.102202

43. Burke RJ, Mikkelsen A. Burnout among Norwegian police officers: potential antecedents and consequences. Int J Stress Manag. 2006;13 (1):64-83. doi:10.1037/1072-5245.13.1.64

44. Levesque M, Blais M, Hess U. Motivational dynamic of burnout and well-being among. African teachers. Can J Behav Sci. 2004;36 (3):190-201. doi:10.1037/h0087229

45. Milfont TL, Denny S, Ameratunga S, Robinson E, Merry S. Burnout and wellbeing: testing the Copenhagen burnout inventory in New Zealand teachers. Soc Indic Res. 2008;89(1):169-177. doi:10.1007/ s11205-007-9229-9

46. Aslan I, Bektaş Ç. Analyzing Burnout Syndrome at Bingol University: Proceedings of the BE-ci 2016 International Conference on Business and Economics, Future Academy; 21-23 September. Selangor, Malaysia; 2016. 43-63.

47. Bikmaz PS. Mental health of those who go to work in the COVID-19 outbreak. Available from: https://www.meslekhastaligi.net/kovid-19salgininda-ise-gidenlerin-ruh-sagligi/. Accessed September 15, 2020

48. Usán Supervía P, Salavera Bordás C, Murillo Lorente V. Psychological analysis among goal orientation, emotional intelligence and academic burnout in middle school students. Int $J$ Environ Res Public Health. 2020;17(21):8160. doi:10.3390/ijerph17218160

49. Valero-Chilleron MJ, Gonzalez-Chorda VM, Lopez-Pena N, CerveraGasch A, Suarez-Alcazar MP, Mena-Tudela D. Burnout syndrome in nursing students: an observational study. Nurse Educ Today. 2019;76:38-43. doi:10.1016/j.nedt.2019.01.014

50. Dimitriu MC, Pantea-Stoian A, Smaranda AC, et al. Burnout syndrome in Romanian medical residents in time of the COVID-19 pandemic. Med Hypotheses. 2020;144:109972. doi:10.1016/j. mehy.2020.109972

51. Wang M, Guan H, Li Y, Xing C, Rui B. Academic burnout and professional self-concept of nursing students: a cross-sectional study. Nurse Educ Today. 2019;77:27-31. doi:10.1016/j.nedt.2019.03.004

52. Zaed I, Jaaiddane Y, Chibbaro S, Tinterri B. Burnout among neurosurgeons and residents in neurosurgery: a systematic review and meta-analysis of the literature. World Neurosurg. 2020;143:529-534. doi:10.1016/j.wneu.2020.08.005

53. Farrell SM, Kadhum M, Lewis T, Singh G, Penzenstadler L, Molodynski A. Wellbeing and burnout amongst medical students in England. Int Rev Psychiatry. 2019;131(7-8):579-583. doi:10.1080/ 09540261.2019 .1675960

54. Lee Y, Lee J. Enhancing pre-service teachers' self-efficacy beliefs for technology integration through lesson planning practice. Comput Educ. 2014;73:121-128. doi:10.1016/j.compedu.2014.01.001

55. Compeau DR, Higgins CA. Computer self-efficacy: development of a measure and initial test. MIS Q. 1995;19(2):189-211. doi:10.2307/ 249688

56. Choi I. The study of self-regulated learning related variables in web-based blended learning: with a focus on school adjustment behavior, academic burnout, self-determination, and participation in e-learning. Open Educ Res. 2014;22(2):237-260.
57. Heo J, Han S. Effects of motivation, academic stress and age in predicting self-directed learning readiness (SDLR): focused on online college students. Educ Inf Technol. 2018;23(1):61-71. doi:10.1007/ s10639-017-9585-2

58. Bolívar A. O planejamento por competência na reforma de Bolonha da educação superior: uma análise crítica. In: Almeida M, Pereira EM, editors. Universidade Contemporânea: Políticas Do Processo De Bolonha. Campinas: Mercado das Letras; 2009:101-128.

59. Amhag L, Hellström L, Stigmar M. Teacher educators' use of digital tools and needs for digital competence in higher education. J Digit Learn Teach Educ. 2019;35(4):203-220. doi:10.1080/21532974.2019.1646169

60. Carretero S, Vuorikari R, Punie Y. DigComp 2.1: the digital competence framework for citizens with eight proficiency levels and examples of use (No. JRC106281). Publications Office of the European Union, Luxembourg; 2017. Available from: https://op.europa.eu/en/publicationdetail/-/publication/bc52328b-294e-11e6-b616-01aa75ed71a1/languageen/format-PDF/source-search. Accessed May 19, 2021.

61. Marza M, Cruz E. Gaming como Instrumento Educativo para una Educación en competencias Digitales desde los Academic Skills Centres. Rev Gen De Inf y Doc. 2018;28(2):489-506. doi:10.5209/ RGID.60805

62. Rodgers S, Maloney B, Ploderer B, Brereton M Managing Stress, Sleep and Technologies: an Exploratory Study of Australian University Students: Proceedings of the 28th Australian Conference on Computer-Human Interaction. 2016. 526-530.

63. European Commission [homepage on the Internet]. The digital competence framework 2.0; 2016. Available from: https://ec.europa.eu/jrc/en/ digcomp/digital-competence-framework. Accessed May 19, 2021.

64. Desjardins FJ. Information and communication technology in education: a competency profile of francophone secondary school teachers in Ontario. Can J Learn Technol. 2005;31(1):1-14.

65. Song L, Singleton ES, Hill JR, Koh MH. Improving online learning: student perceptions of useful and challenging characteristics. Internet High Educ. 2004;7(1):59-70. doi:10.1016/j.iheduc.2003.11.003

66. Álvarez E, Núñez P, Rodríguez C. Adquisición y carencia académica de competencias tecnológicas ante una economía digital. Rev Lat De Comun Soc. 2017;72:540-559.

67. Reinecke L, Oliver MB. Media use and well-being: status quo and open questions. In: Reinecke L, Oliver MB, editors. The Routledge Handbook of Media Use and Well-Being: International Perspectives on Theory and Research on Positive Media Effects. New York: Routledge; 2016:3-13.

68. Sonnentag S, Pundt A. Media use and well-being at the work-home interface. In: Reinecke L, Oliver MB, editors. The Routledge Handbook of Media Use and Well-Being. New York: Routledge; 2017:341-354.

69. Blayone TJ, Mykhailenko O, van Oostveen R, Grebeshkov O, Hrebeshkova O, Vostryakov O. Surveying digital competencies of university students and professors in Ukraine for fully online collaborative learning. Technol Pedagogy Educ. 2018;27(3):279-296. doi:10.1080/1475939X.2017.1391871

70. Worldmeter [homepage on the Internet]. Countries in the world by population; 2021. Available from: https://www.worldometers.info/ world-population/population-by-country/. Accessed April 27, 2021.

71. The World Bank [homepage on the Internet]. Individuals using the Internet ( $\%$ of population). Available from: https://data.worldbank. org/indicator/IT.NET.USER.ZS. Accessed April 27, 2021.

72. Statista [homepage on the Internet]. Internet usage in India - statistics \& facts. Available from: https://www.statista.com/topics/2157/inter net-usage-in-india/\#dossierSummary. Accessed May 21, 2021.

73. Speedtest [homepage on the Internet]. Speedtest global index. Available from: https://www.speedtest.net/global-index. Accessed April 27, 2021.

74. UNESCO Institute for Statistics [homepage on the Internet]. School enrollment, tertiary (\% gross) - Country Ranking. Available from: https://www.indexmundi.com/facts/indicators/SE.TER.ENRR/rank ings. Accessed May 21, 2021. 
75. Kutlu R. What we have learned about the new coronavirus pandemic, current diagnostic and therapeutic approaches and the situation in turkey. Turkish J Family Med Prim Care. 2020;14(2):329-344. doi:10.21763/tjfmpc.729917

76. Yamamoto GT, The AD. Coronavirus and the rising of online education. J Univ Res. 2020;3(1):25-34.

77. Topp CW, Østergaard SD, Søndergaard S, Bech P. The WHO-5 well-being index: a systematic review of the literature. Psychother Psychosom. 2015;84(3):167-176. doi:10.1159/000376585

78. Lemyre L, Tessier R. Measuring psychological stress. Concept, model, and measurement instrument in primary care research. Can Fam Physician. 2003;49:1159.

79. Blayone T. Reexamining digital-learning readiness in higher education: positioning digital competencies as key factors and a profile application as a readiness tool. Int J E-Learn. 2018;17(4):425-451.

80. Desjardins FJ, VanOostveen R. Faculty and student use of digital technology in a "laptop" university. Paper presented at Ed-Media 2015 World Conference on Educational Media and Technology; 2015; Montreal, Quebec, Canada.

81. Desjardins FJ, Lacasse R, Bélair LM. Toward a definition of four orders of competency for the use of information and communication technology (ICT) in education. Paper presented at the Computers and Advanced Technology in Education; 2001, Banff, Canada.
82. Ryciuk U, Nazarko J. Model of trust-based cooperative relationships in a supply chain. J Bus Econ Manag. 2020;21(5):1225-1247. doi:10.3846/jbem.2020.12829

83. Daumiller M, Rinas R, Hein J, Janke S, Dickhäuser O, Dresel M. Shifting from face-to-face to online teaching during COVID-19: the role of university faculty achievement goals for attitudes towards this sudden change, and their relevance for burnout/engagement and student evaluations of teaching quality. Comput Human Behav. 2021;118:106677. doi:10.1016/j.chb.2020.106677

84. Liang SC, Hsieh AT. The role of organizational socialization in burnout: a Taiwanese example. Soc Behav Pers. 2008;36 (2):197-216. doi:10.2224/sbp.2008.36.2.197

85. Thomas CH, Lankau MJ. Preventing burnout: the effects of LMX and mentoring on socialization, role stress, and burnout. Hum Resour Manage. 2009;48(3):417-432. doi:10.1002/hrm.20288

86. Podsakoff PM, MacKenzie SB, Podsakoff NP. Sources of method bias in social science research and recommendations on how to control it. Ann Rev Psychol. 2012;63(1):539-569. doi:10.1146/ annurev-psych-120710-100452
Psychology Research and Behavior Management

\section{Publish your work in this journal}

Psychology Research and Behavior Management is an international, peer-reviewed, open access journal focusing on the science of psychology and its application in behavior management to develop improved outcomes in the clinical, educational, sports and business arenas. Specific topics covered in the journal include: Neuroscience, memory and decision making; Behavior modification and management; Clinical

\section{Dovepress}

applications; Business and sports performance management; Social and developmental studies; Animal studies. The manuscript management system is completely online and includes a very quick and fair peer-review system, which is all easy to use. Visit http://www. dovepress.com/testimonials.php to read real quotes from published authors. 